\title{
АНАЛИЗ И ПРОГНОЗИРОВАНИЕ ТЕПЛОМАССООБМЕННЫХ ПРОЦЕССОВ И РАДИАЦИОННОГО СОСТОЯНИЯ НОВОГО БЕЗОПАСНОГО КОНФАЙНМЕНТА И РАЗРУШЕННОГО БЛОКА ЧАЭС НА ОСНОВЕ CFD-МОДЕЛИРОВАНИЯ
}

\author{
Круковский П.Г., доктор техн. наук, Метель М.А., Полубинский А.С., канд. техн. наук
}

Институт технической теплофизики НАН Украины, ул. Желябова, 2а, Киев-57, 03057, Украина

В роботі розглядаються призначачення і конструкція Нового Безпечного Конфайнменту (НБК), що збудований та насунутий на Об’єкт «Укриття» (ОУ) Чорнобильської АЕС. Обгрунтовується необхідність аналізу та прогнозування сумісних термогазодинамічних та вологісних процесів в ОУ і НБК, які визначють 100-річний ресурс НБК.

Для цього розроблена тривимірна комп'ютерна CFD-модель, яка на засаді аналізу вказаних вище процесів дозволяє також аналізувати процес розповсюдження радіоактивних аерозолів у об’ємах ОУ, НБК і оточуючого середовища.

Библ. 1, рис. 4.
В работе рассматриваются назначение и конструкция Нового Безопасного Конфайнмента (НБК), построенного и надвинутого на Объект «Укрытие» (ОУ) Чернобыльской АЭС . Обосновывается необходимость анализа и прогнозирования совместных термогазодинамических и влажностных процессов в ОУ и НБК, которые определяют 100-летний ресурс НБК. Для этого разработана трехмерная компьютерная CFD-модель, которая на основе анализа указанных выше процессов позволяет также анализировать процесс распространения радиоактивных аэрозолей в объёмах ОУ, НБК и окружающей среде.
This paper deals with the purpose and design of the New Safe Confinement (NSC), which was built and slide over Object "Shelter" (OS) of the Chernobyl nuclear power plant.

The justification of necessity analyzing and forecasting providing for joint termogazynamic and humidity processes in the OS and the NSC, which determine the 100-year lifetime for NSC. A 3D CFD-computer model was developed, which allows also to analyze the radioactive aerosols propagation in the OS and NSC volumes as well as the environment on the base of above mentioned processes.

Ключевые слова: Новый Безопасный Конфайнмент, тепло- и массобмен, радиоактивное загрязнение, СFDмоделирование.

Новый Безопасный Конфайнмент (НБК), построенный в течение 5 лет и надвинутый на Объект «Укрытие» (ОУ) Чернобыльской АЭС в ноябре 2016г. (рис. 1), является защитным сооружением, включающим в себя оборудование для извлечения из разрушенного 4-го энергоблока ЧАЭС материалов, содержащих ядерное топливо, преобразования этого энергоблока в экологически безопасную систему и обеспечения безопасности персонала, населения и окружающей среды. НБК представляет собой комплекс из трех инженерно-технических решений: стальных конструкций в виде Арки, накрывающих Объект «Укрытие» (ОУ), технологического здания, расположенного в западной части Арки, где установлено большинство систем жизнеобеспечения и контроля [1].

Для обеспечения защиты окружающей среды и гарантирования долговременного сопротивления коррозии, структурная часть Арки (рис. 1, позиция 1) внутри и снаружи обшита двумя металлическими оболочками, внешней 2 и внутренней 3. Пространство между оболочками Арки называется кольцевым (межарочным) пространством, а объем между внутренней оболочкой и строениями под Аркой называется основным объемом.

В кольцевом пространстве и основном объеме предусмотрены системы вентиляции, которые будут обеспечивать требуемый режим влажности (с целью снижения до минимума коррозии металлических конструкций кольцевого пространства) и предотвращать попадание аэрозольных выбросов в окружающую среду, которые могут возникнуть в основном объеме Арки при демонтаже конструкций ОУ.

НБК, который спроектирован, построен и надвинут на ОУ консорциумом VINCI Construction Grands Projets / Bouygues Travaux Publics NOVARKA (HOBAPKA), должен предотвратить утечки радиоактивных материалов из разрушенного реактора №4 в окружающую среду при его разборке. Общие геометрические размеры Арки НБК составляют: высота около 109 м, длина около 164 м, ширина около 260 м. Объем воздуха между внутренней и внешней обшивками Арки НБК (кольцевое пространство, рис. 1, поз. 1), составляет около 1,0 млн. м3, а основного объема НБК внутри Арки - около 1,4 млн. м3. Объем Объекта «Укрытие» составляет около 1,0 млн. м3. Общий вес Арки составляет около 33 тыс. тонн.

Одной из важных инженерных систем НБК является система вентиляции, которая прежде всего должна обеспечить требуемый режим относительной влажности (не более 40 \%) и уровень превышения давления воздуха (50..75 Па) в кольцевом пространстве Арки НБК, а также вентиляцию и поддержание слабого вакуума ( $\approx-5$ Па) в основном обьеме Арки НБК при различных метеорологических условиях. Необходимость поддержания низкого уровня относительной влажности в кольцевом пространстве Арки НБК продиктована требованием снижения до минимума коррозии металлических конструкций, расположенных в кольцевом простран- 
стве, для обеспечения 100-летнего ресурса Арки НБК.

Система вентиляции состоит из двух подсистем,подсистемы вентиляции и осушения кольцевого пространства для обеспечения указанного выше уровня относительной влажности воздуха и подсистемы вентиляции основного обьема НБК для обеспечения поступления свежего воздуха в места работы персонала НБК и отвода воздуха из мест с наибольшим количеством радиоактивных аэрозолей, прежде всего пространства над ОУ.

Поскольку влажностный режим воздушных обьемов Арки НБК напрямую зависит от температурного и газодинамического режимов в этих обьемах, то для деталь- ного анализа работоспособности системы вениляции НБК необходима разработка инструмента, способного выполнить такой анализ. В качестве такого инструмента было выбрано трехмерное CFD (Computational Fluid Dynamic)-компютерное моделирование.

Целью статьи является описание выбранной модели и основных результатов ее применения для детального анализа и прогнозирования совместных термогазодинамических и влажностных процессов в ОУ и НБК, которые зависят от работоспособности системы вентиляции НБК и определяют его 100-летний ресурс, а также для анализа процесса распространения радиоактивных аэрозолей в объёмах ОУ, НБК и окружающей среде.

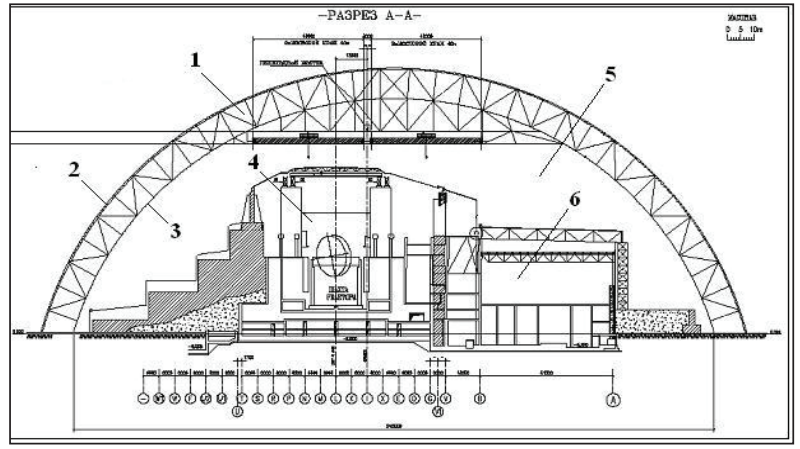

a)

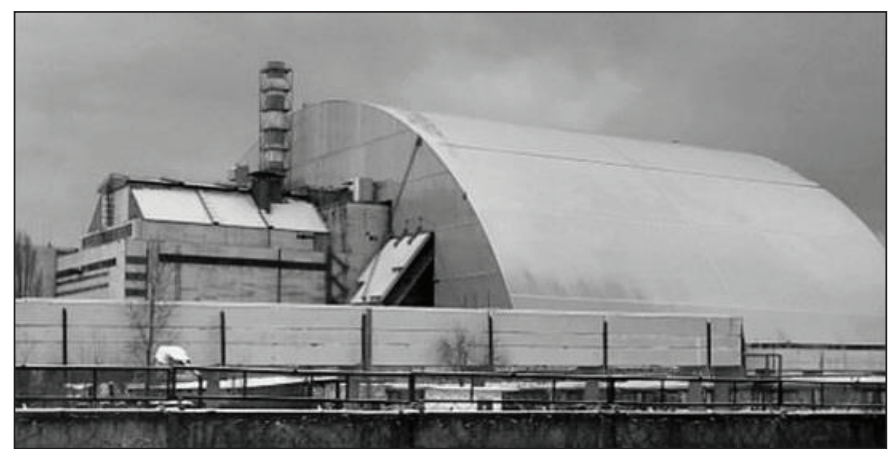

б)

Рис. 1. Схема Объекта «Укрытие» и Нового Безопасного Конфайнмента в поперечном сечении (а) и их фото после надвижки НБК на ОУ (б).

На рис. а: 1 - стальные конструкции и кольцевое пространство Арки НБК, 2 - наружная оболочка, 3 - внутренняя оболочка, 4-Объект «Укрытие» и разрушенный реактор, 5 - основной объем НБК, 6 -машзал.

Физическая модель температурных и газодинамических процессов, происходящих в НБК, представляется следующей. Температурно-влажностный режим в кольцевом пространстве Арки НБК, основном объеме и в строительных конструкциях ОУ формируется в результате сложного взаимодействия происходящих там аэродинамических и тепломассообменных процессов (рис. 1). Это процессы: теплопроводности через элементы строительных конструкций, конвективный теплообмен между воздушными потоками и поверхностями Арки НБК и ОУ, смешение поступающих в объем кольцевого пространства (КП) и основной объем Арки НБК (а также отводимых из указанных объемов) воздушных потоков с различной температурой и влажностью, тепло, поступающее в основной объем из ОУ (разрушенного блока №4) от системы освещения Арки и из деаэраторной этажерки.

Основным источником теплопоступления в КП в летний период является солнечная радиация и конвективный теплоподвод от ветрового потока, воздействующего на внешнюю поверхность Арки. Тепловые потоки с внешней поверхности Арки посредством теплопроводности через металлические элементы конструкции Арки НБК передаются в межарочное воздушное пространство и основной обьем НБК.
В зимний период основными механизмами теплоотвода с внешней поверхности Арки в окружающее пространство также является радиационно-конвективный теплоперенос.

Другими источниками теплопоступления в кольцевое пространство являются потоки осушенного и подогретого воздуха, нагнетаемого из окружающей среды, а также подогреваемые рециркуляционные воздушные потоки. Эти воздушные потоки формируются путем отбора воздуха из кольцевого пространства, его подогрева до определенной температуры и последующего возвращения в объем кольцевого пространства. Отвод теплоты из кольцевого пространства, кроме теплопотерь в зимний период, происходит также за счет инфильтрационных перетоков воздуха через неплотности в оболочках арочных конструкций во внешнее воздушнюю среду и основной объем Арки НБК. Указанные воздушные перетоки возникают вследствие организации повышенного давления (на 50..75 Па) относительно окружающей среды) в кольцевом пространстве, что должно исключить неорганизованное проникновение в кольцевое пространство влажного воздуха из внешней среды, а также исключит проникновение радиоактивных аэрозольных выбросов из основного объема через кольцевое пространство в окружающую среду. 
Температурно-влажностный режим основного объема Арки НБК формируется за счет:

- радиационно-конвективного взаимодействия поверхностей внутренней оболочки Арки с поверхностями конструкций кольцевого пространства и строительными конструкциями ОУ;

- проникновения воздуха и влаги из окружающей среды через щели между вертикальными стенами Арки НБК и строительными конструкциями ОУ (рис. 1, б, позиции 1, 2);

- потоков теплоты и массы из кольцевого пространства в основной объем;

- источников внутреннего тепловыделения в ОУ и осветительных приборах;

- подачи и удаления воздуха в основном объеме системой приточно-вытяжной вентиляции;

- переноса теплоты из и в основной объем Арки НБК от поверхности грунта и фундаментов, на которых расположен НБК.
- тепловой емкости массивных металлических конструкций Арки НБК, массивных бетонных конструкций ОУ, грунта и фундамента, на которых расположен НБК при рассмотрении длительных нестационарных процессов дневных, месячных и годичных циклов.

Температурно-влажностный режим этого объема Арки должен быть таким, чтобы давление в нем было несколько ниже, чем давление воздуха в кольцевом пространстве, а также в окружающем пространстве. При таких условиях исключается самопроизвольный переток загрязненного воздуха из основного объема Арки НБК во внешнюю окружающую среду и междуарочное кольцевое пространство, в котором необходимо поддерживать требуемые тепловлажностные условия воздушной среды.

Для выполнения работы была создана 3D CFDмодель, включающая в себя как части модели Арки НБК, так и всех объектов под Аркой, включая Объект «Укрытие», грунты и фундаменты (рис. 2).

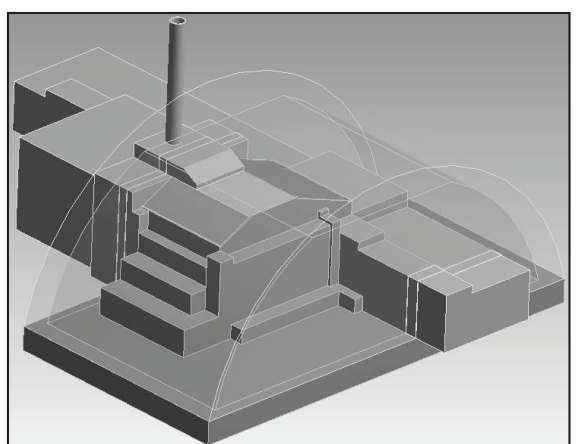

a)

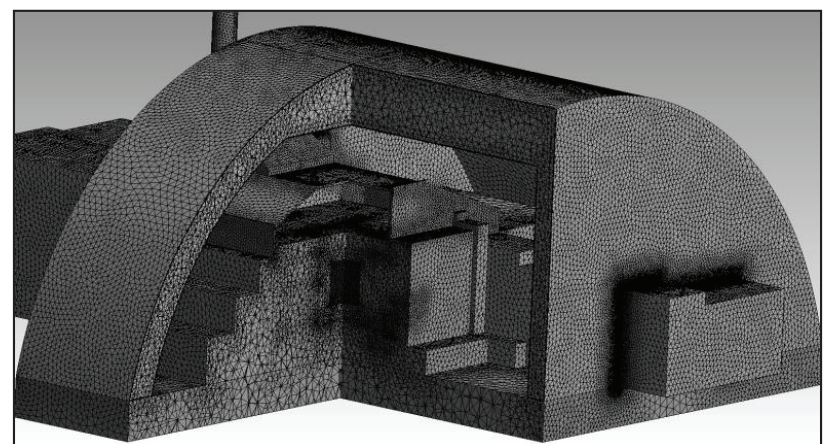

б)

Рис. 2. Части геометрической (а) и сеточной моделей Арки НБК (б) и всех объектов под Аркой, включая Объект «Укрытие», грунты и фундаменты.

На внешней оболочке Арки НБК имеют место естественные условия сопряженного радиационно-конвективного теплообмена и условия массообмена слабофильтрующегося воздуха и влажности между поверхностями оболочки и внешней средой при различных направлениях и силе ветра, обтекающего НБК. Между всеми твердыми поверхностями НБК, ОУ, поверхностью земли и воздухом, обтекающим эти поверхности, также задавались условия сопряженного теплообмена. Воздухо- и влагообмен между основным объемом и окружающей средой осуществлялся посредством системы вентиляции и протечек воздуха и влаги из окружающей среды через щели между вертикальными стенами Арки НБК и строительными конструкциями ОУ. Величина этих протечек также зависит от направления и силы ветра, обтекающего НБК. Влияние земли и фундаментов учитывалось посредством включения в основную модель области решения и дополнительной сетки, охватывающей грунт и фундаменты под Аркой НБК на глубину 15 м (рис. 2). Температура грунта на глубине 15 м стабильная и принималась равной $10^{\circ} \mathrm{C}$.

Разработанная и кратко описанная выше модель термогазодинамических и влажностных процессов в воздушных обьемах Арки НБК, всех строительных кон- струкциях ОУ и фундаментах и грунтах под ними была использована для детального анализа распределения температур и влажности в кольцевом и основном объемах НБК и ОУ при различных климатических условиях в стационарных и нестационарных режимах, а также прогнозировании тепловлажностного состояния ОУ и НБК при отказах различных частей вентиляционного оборудования. На рис. 3 приведен пример такого распределения температур и влажности в кольцевом и основном объемах НБК и ОУ при стационарном режиме в летнее время при температуре окружающего воздуха $30^{\circ} \mathrm{C}$, относительной влажности $100 \%$ и отсутствии ветра.

Проведенные исследования показали, что система вентиляции в целом работоспособна в диапазоне заданных климатических условий с изменением температуры окружающего воздуха от -22 до $+30{ }^{\circ} \mathrm{C}$, относительной влажности от 50 до $100 \%$ и силе ветра от 0 до 25 м/с. Временное превышение уровня влажности в кольцевом пространстве наблюдалось лишь при силе ветра, превышающей 7,2 м/с.

Поскольку разработанная модель позволяет рассчитывать потоки воздуха как внутри НБК и ОУ, так и внешнее обтекание НБК, она также может моделиро- 
вать распространение радиоактивных аэрозолей (РА) из разрушенного реактора либо в виде второй фазы, либо в виде дискретных частиц, переносимых этими воздушными потоками (рис. 4). Моделирование переноса массы пыли со средним диаметром 5 мкм производится

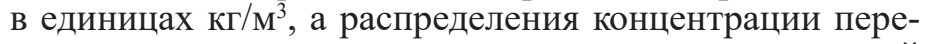
считываются через весовую активность радиоактивной пыли Бк/кг для 1 кг пыли.
Такая возможность очень важна для анализа радиационного состояния внутреннего воздушного пространства НБК, где работает персонал (рис. 4, в), а также для анализа распространения РА за пределы НБК в окружающую среду (рис. $4 a, \sigma)$.

Авторы выражают благодарность компании NOVARKA и программе SPS HATO за финансовую поддержку работы.

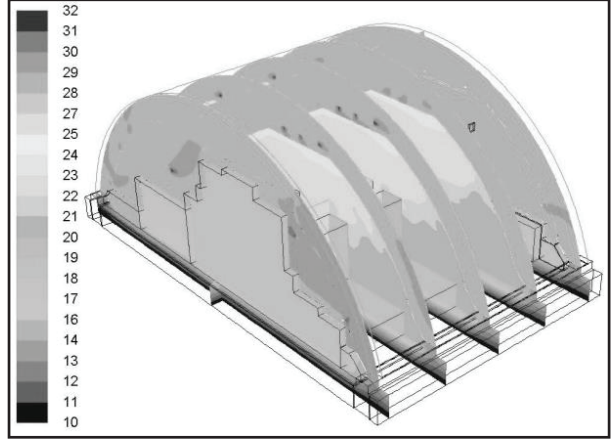

a)

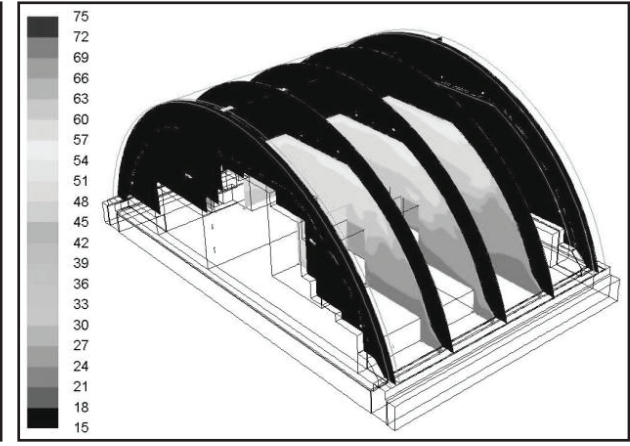

б)

Рис. 3. Распределения температур (а) и влажности (б) в кольцевом и основном объемах ОК и НБК.
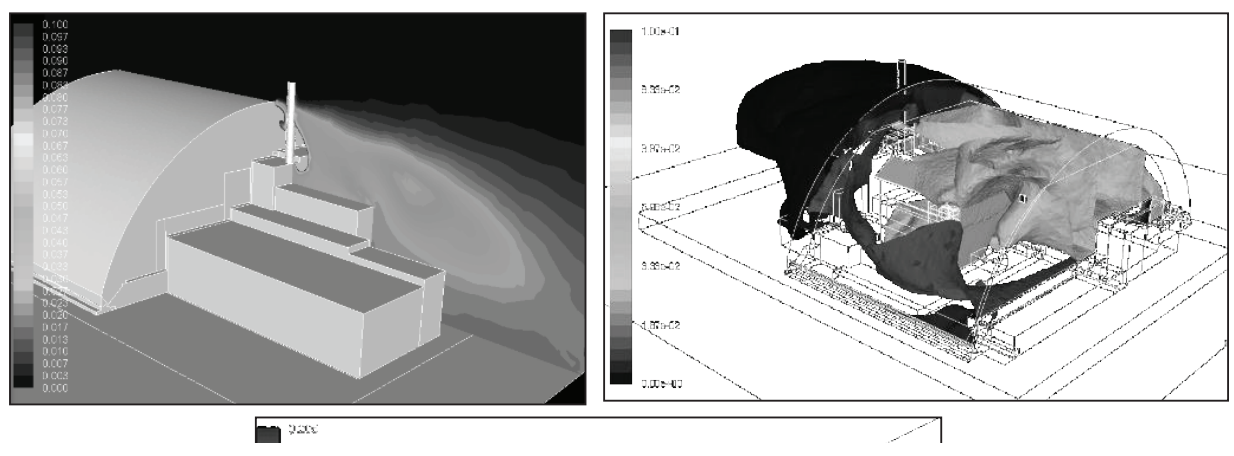

a)

б)

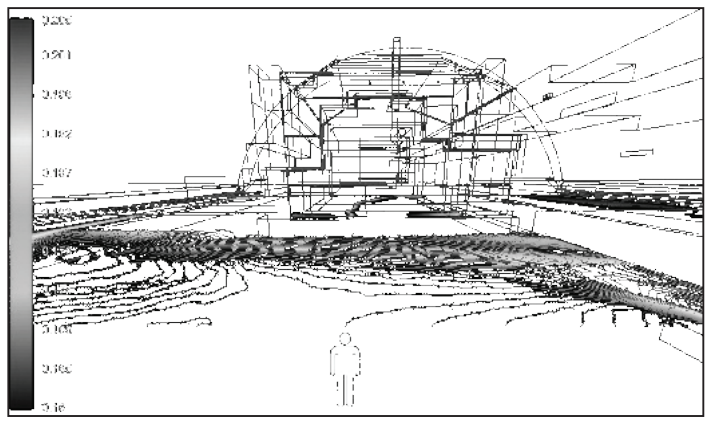

B)

Рис. 4. Распределение концентрации РА, Бк/м3, исходящее из НБК в окруюающую среду (а), изоповерхности концентраций РА внутри и снаружи НБК (б), а такэсе изолинии концентраций РА внутри НСК на высоте 1,5 м от земли в зоне возможной деятельности персонала (в).

\section{Bblводbl}

1. Рассматрены назначение и конструкция Нового Безопасного Конфайнмента (НБК), построенного и надвинутого на Обьект «Укрытие» (ОУ) Чернобыльской
АЭС, который должен предотвратить утечки радиоактивных материалов из разрушенного реактора №4 в окружающую среду при его разборке.

2. Обосновывается необходимость анализа и про- 
гнозирования совместных термогазодинамических и влажностных процессов в ОУ и НБК, которые определяют 100-летний ресурс НБК.

3. Для выполнения анализа и прогнозирования термогазодинамических и влажностных процессов в ОУ и НБК разработана трехмерная компьютерная CFD-модель, которая позволила проверить работоспособность системы вентиляции НБК при возможных климатических условиях. Проведенные исследования показали, что система вентиляции в целом работоспособна в диапазоне заданных климатических условий.

4. Показана возможность использования разрабо- танной модели для анализа и прогнозирования распространения радиоактивных аэрозолей из разрушенного реактора и ОУ в объём НБК и далее в окружающую среду.

\section{ЛИТЕРАТУРА}

1. Кониеептуальный проект Нового Безопасного Конфайнмента, Чернобыльская Атомная Электростанция - Блок 4, Государственное Специализированное Предприятие "Чернобыльская Атомная Электростанция (ГСП ЧАЭС )”, Киевская обл ., Украина, 2003 г.

\section{ANALYSIS AND PREDICTION OF HEAT AND MASS TRANSFER PROCESSES AND RADIOACTIVE STATE OF THE NEW SAFE CONFINEMENT AND DESTROYED UNIT OF CNPP BASED ON CFD-MODELING}

\section{Krukovskiy P.G., Dr., Metel M.A., Polubinskyi A.S.}

Institute of Engineering Thermophysics of National Academy of Sciences of Ukraine,

ul. Zhelyabova, 2a, Kiev-57, 03057, Ukraine

This paper deals with the purpose and design of the New Safe Confinement (NSC), which was built and slide over Object "Shelter" (OS) of the Chernobyl nuclear power plant. The justification of necessity analyzing and forecasting providing for joint termogazynamic and humidity processes in the OS and the NSC, which determine the 100-year lifetime for NSC. A 3D CFD-computer model was developed, which allows also to analyze the radioactive aerosols propagation in the OS and NSC volumes as well as the environment on the base of above mentioned processes.

Ref. 1, fig. 4.

Key words: New Safe Confinement, heat and mass transfer, radioactive pollution, CFD-modeling.

1. Kontseptual'nyy proyekt Novogo Bezopasnogo Konfaynmenta, Chernobyl'skaya Atomnaya Elektrostantsiya - Blok 4 [Conceptual design of the New Safe Confinement, Chernobyl Nuclear Power Plant-Block 4], Gosudarstvennoye Spetsializirovannoye Predpriyatiye "Chernobyl'skaya Atomnaya Elektrostantsiya (GSP CHAES )" [State Specialized Enterprise "Chernobyl Atomic Power Station (SSE ChNPP)"], Kiyevskaya obl ., Ukraina, 2003 g. (Rus)

Получено 11.04.2017 Received 11.04.2017 


\section{Шановні передплатники! \\ 20 квітня розпочинається передплата на періодичні видання на 2 півріччя 2017 р.}

Оформити передплату на журнал «Промышленная теплотехника»

(підписний індекс журналу - 74405)

можна за «Каталогом видань України»:

•у відділеннях поштового зв'язку

•в операційних залах поштамтів

•в пунктах приймання передплати

•на сайті ДП «Преса» www.presa.ua

Рукописи статей до журналу слід подавати у повній відповідності до «Вимог», які розміщені на сайті www.ittf.kiev.ua у розділі - Журнал «Промышленная теплотехника».

Електронні адреси редакції -

shmorgun@nas.gov.ua; Martiuk@nas.gov.ua,shmorgun@ittf.kiev.ua.

Kamaл02

budants

Уicpaïinu

2017

II mibpinms?

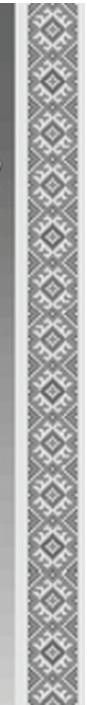

